\title{
Optimization of Electrical Parameters for Production of Carbon Nanotubes
}

\author{
Sayantan Chattopadhyay, Kalyan Kumar Singh \\ Department of Mechanical Engineering \& Mining Machinery Engineering Indian School of Mines (ISM), Dhanbad, India \\ Email: sayantanchattopadhyay@ymail.com
}

Received July 20, 2012; revised August 22, 2012; accepted August 30, 2012

\begin{abstract}
For more than two decades, there had been extensive research on the production of carbon nanotubes (CNT) and optimization of its manufacture for the industrial applications. It is believed that they are the strong enough but most flexible materials known to mankind. They have potential to take part in new nanofabricated materials. It is known that, carbon nanotubes could behave as the ultimate one-dimensional material with remarkable mechanical properties. Moreover, carbon nanotubes exhibit strong electrical and thermal conducting properties. In the process of optimizing the production in line with the industrial application, the researchers have found a new material to act as an anode i.e. coal, which is inexpensive as compared to graphite. There are various methods such as arc discharge, laser ablation, chemical vapour deposition (CVD), template-directed synthesis and the use of the growth of CNTs in the presence of catalyst particles. The production of carbon nanotubes in large quantities is possible with inexpensive coal as the starting carbon source by the arc discharge technique. It is found that a large amount of carbon nanotubes of good quality can be obtained in the cathode deposits in which carbon nanotubes are present in nest-like bundles. This paper primarily concentrates on the optimising such parameters related to the mass production of the product. It has been shown through Simplex process that based on the cost of the SWNT obtained by the arc discharge technique, the voltage and the current should lie in the range of $30-42 \mathrm{~V}$ and 49 - 66 A respectively. Any combination above the given values will lead to a power consumption cost beyond the final product cost, in turn leading to infeasibility of the process.
\end{abstract}

Keywords: Coal; Carbon Nanotubes; SWCNT; Simplex; Optimization

\section{Introduction}

In 1985, Drexler proposed a molecular bearing consisting of two graphitic nanotubes of different diameter, which are concentrically arranged. It was a virtual operation inside a computer. This dream, however, has become more realistic by the discovery of carbon nanotubes. There had been revolutionizing researches on the production of Carbon Nanotubes from last twenty years and optimising its manufacture for the industrial applications. It has been thought that they are the strongest but most agile materials known to humankind, and thus have potential to take part in new nanofabricated materials as additives. It has been shown that carbon nanotubes could behave as the ultimate one-dimensional material with remarkable mechanical properties. Carbon nanotubes exhibit strong electrical and thermal conducting properties. Study of the past researches on the production of carbon nanotubes from coal revealed that most of the researches concentrate on producing CNT by arcing electrodes, produced separately by mixing the crushed coal with coal tar followed by molding process. However, the only process till date that has shown a positive adaptation to direct coal application is thermal plasma jet technique.

With the extensive research in the production of the Carbon Nanotubes, the requirement of optimising the process parameters are realised. This paper concentrates on the optimising such parameters related to the mass production of the product. It has been found through calculation that the only determining parameter in the arc discharge technique is the power of the equipment, in terms of voltage and current, and it is seen that on optimisation of these parameters, the cost of the process reduces drastically.

\section{CNT Production through Arc Discharge Technique}

Carbon nanotubes (CNTs) have been used in various fields of research due to their unique properties. There are various methods such as arc discharge, laser ablation, chemical vapour deposition (CVD), template-directed synthesis and the use of the growth of CNTs in the presence of catalyst particles [1]. Special ambient gas is required for the fabrication of CNTs, in order to prevent the oxidation of carbon at high temperature. 
The production of carbon nanotubes in large quantities and other nanomaterials as by-products is possible with inexpensive coal as the starting carbon source by the arc discharge technique $[2,3]$. It has been found that a large amount of carbon nanotubes of good quality can be obtained in the cathode deposits in which carbon nanotubes are present in nest-like bundles. In the past decades, various alternate synthesis strategies and methods have been explored and developed in the hope of mass-producing cheap and high quality Single-walled carbon nanotubes (SWNT). Compared to other methods, the arc discharge is the simplest, cheapest and easy to implement and it has been used because of its potential merits to make a massive production. The mineral matter in raw coals may also play an important part in the formation process of carbon nanotubes. An approach of production of Singlewalled carbon nanotubes (SWNT) had been adopted in 2004 [4] where the coal is crushed and sieved with 150 $\mu \mathrm{m}$ mesh and mixed with coal tar and molded to form coal rods used for anode with a graphite cathode for the arc discharge process. Similar approach had been made by the same researchers for the production of Doublewalled carbon nanotubes (DWNTs) which were synthesized from coal in large quantity by arc-discharge method in hydrogen-free atmosphere [5], and was systematically examined using scanning electron microscopy, transmission electron microscopy, high-resolution transmission electron microscopy and Raman spectroscopy. In the case of coal-derived carbons, the breaking-up scheme involved in the arc-discharge process significantly differs from that of graphite because of the striking difference in their textures. Coal or coal-derived carbons feature macromolecular structures rather than the lattice structure of graphite. In their chemical structures there exist many weak binding linkages between carbon polymeric units such as polymerized aryl structures. In the fast paralyses process under arc plasma conditions, these weak linkages would be broken up rather easily to release a variety of reactive fragments of hydrocarbon molecules such as alkynes and aromatic species. However, the production of SWNTs has seen a typical use of an iron wire mesh utilised between the electrodes and the carbonaceous matter is found on the wire mesh.

A possibility of the production of carbon nanotubes from heavy hydrocarbon resources had been proposed in 2008 [6]. Before the use of heavy hydrocarbons, pure compound, toluene was used as the pure substrate to establish the reaction system for the production of carbon nanotubes. Toluene was fed by a mist-spray feeding system with a carrier gas as 9:1 mixture of nitrogen and hydrogen at $100 \mathrm{ml} / \mathrm{min}$, and following the reaction at $750^{\circ} \mathrm{C}$ catalysed by $9.8 \%$ (by weight) ferrocene, Carbon nanotubes were found in the carbonaceous product deposited on inner wall of a quartz tube and at the exit of the tube. The product was observed by scanning electron microscopy and analyzed by temperature-programmed oxidation experiments to identify the presence of carbon nanotubes. Based on the reaction system and reaction conditions with toluene, the production of nanotubes was examined by using heavy hydrocarbons such as asphalttene and maltene fractions from natural asphalt. Under selected reaction conditions including the reaction temperature and the amount of the catalyst, carbon nanotubes with a diameter of $30-60 \mathrm{~nm}$ were found.

\section{Optimisation of Voltage and Current Used in the Carbon Nanotube Production}

It is known that Voltage and Current constitute the Power requirements for an electrically operated machine. Same in the case of the production of CNT from the arc discharge method, the electrical power signifies the characteristics of the arc that is generated between the two electrodes, in this case, one coal-based and the other, graphite. For the optimisation process, the total cost of the input materials must be lesser than that of the output product.

It is seen from the past experimental research works [2,3,7-9], the work has been done on Bituminous and An- thracite coal samples. From the domestic coal, cost fixed by Coal India Ltd. the coal costs are as stated in Table 1.

For Anthracite and Bituminous coal, we choose Grade $\mathrm{B}$ and $\mathrm{F}$ respectively [10]. Therefore, the cost would be Rs.3590 per tonne and Rs. 1130 per tonne respectively, if we take the maximum cost of the above grades from different companies, from the Table 1.

The coal-based electrode specifications for the arc discharge process are found from the experimental works in the past. With the aim of the maximum cost involved in the production of the coal-based electrode, the electrode with maximum volume is selected, as it is the electrode that involves the maximum amount of coal and thus the cost. Out of the several independent researches the specification of diameter $10 \mathrm{~mm}$ and length $200 \mathrm{~mm}$ is chosen as it gives the maximum volume as compared to the other electrodes in the other researches.

$$
\begin{aligned}
& \text { Therefore, electrode volume }=\frac{\pi}{4} d^{2} \times l=\frac{\pi}{4} \times 10^{2} \\
& \times 200=15707 \mathrm{~mm}^{3}=1.57 \times 10^{-5} \mathrm{~m}^{2} \\
& \text { Bank density of coal is } 1346 \mathrm{~kg} / \mathrm{m}^{3} \\
& \text { So, Bank Weight of the powdered coal used }=1.57 \times \\
& 10^{-5} \times 1346=0.021 \mathrm{~kg} \\
& \text { Maximum Cost of the coal is taken to be Rs.3.5/kg } \\
& \text { Therefore, Cost of the coal used }=3.5 \times 0.021=0.073 \\
& \text { The cost of power is to be calculated next. In a typical } \\
& \text { experiment [9], the current was taken to be } 100 \mathrm{~A} \text { and the } \\
& \text { voltage was taken to be } 36 \mathrm{~V} \text {. } \\
& \text { Therefore, Power }=V \times I=30 \times 100=3000 \mathrm{~W}=3 \\
& \text { KW }
\end{aligned}
$$


Table 1. Basic price of run of mine non-long-flame noncoking coal [11].

\begin{tabular}{cccccccc}
\hline \multirow{2}{*}{ Field/Co. } & \multicolumn{7}{c}{ Cost of grades of coal in rupees/tonne } \\
\cline { 2 - 7 } & $\mathrm{A}$ & $\mathrm{B}$ & $\mathrm{C}$ & $\mathrm{D}$ & $\mathrm{E}$ & $\mathrm{F}$ & $\mathrm{G}$ \\
\hline ECL & 3690 & 3590 & 1680 & 1350 & 1010 & 790 & 560 \\
$\begin{array}{c}\text { ECL/ } \\
\text { Mugma }\end{array}$ & 3690 & 3590 & 1950 & 1610 & 1290 & 960 & 620 \\
$\begin{array}{c}\text { ECL/Rajm } \\
\text { ahal }\end{array}$ & - & - & - & - & 1330 & 1130 & 910 \\
BCCL & 3690 & 3590 & 1630 & 1350 & 1080 & 860 & 610 \\
CCL & 3690 & 3590 & 1590 & 1300 & 1030 & 820 & 590 \\
NCL & 3690 & 3590 & 1430 & 1200 & 960 & 750 & 560 \\
SECL & 3690 & 3590 & 1370 & 1140 & 950 & 740 & 560 \\
MCL & 3690 & 3590 & 1370 & 1140 & 950 & 740 & 560 \\
\hline
\end{tabular}

(A-Graphite/high quality anthracite; B-Anthracite $(\mathrm{C}: \mathrm{H}>30)$; C-Anthracite (C:H $~ 26$ - 30); D-Semi-anthracite; E-Semi-bituminous; FBituminous; G-Low quality bituminous).

Table 2. Carbon nanotube price list [12].

\begin{tabular}{cccc}
\hline \multirow{2}{*}{$\begin{array}{c}\text { Package } \\
\text { (gram) }\end{array}$} & \multicolumn{2}{c}{ SWNT } & DWNT \\
\cline { 2 - 4 } & $\begin{array}{c}\text { High purity* } \\
(\$)\end{array}$ & $\begin{array}{c}\text { Arc CNT* } \\
(\$)\end{array}$ & High purity* (\$) \\
\hline 1 & 210 & 83 & 210 \\
10 & 1600 & 700 & 1600 \\
50 & 6850 & 3050 & 6850 \\
100 & 12400 & 5500 & 12400 \\
500 & Call & Call & Call \\
1000 & Call & Call & Call \\
\hline
\end{tabular}

*The High Purity CNT (more than $90 \%$ pure) is not achievable by Arc Discharge Method, as per different researches, and thus the cost of the Arc CNT, made from Arc Discharge Method, is always less than the former. However, DWNTs are not the common by-product from the Arc Discharge Method.

The rate of anode feed in the experiment is taken to be $10 \mathrm{~mm}$ for $2 \mathrm{hrs}$. The length of the electrode in the experiment is $75 \mathrm{~mm}$. So, the total experiment time equals 15 hrs. For that time the 45 units of electricity is consumed $(1 \mathrm{KWhr}=1$ unit of consumed electricity).

As per the regulations of Calcutta Electricity Supply Corporation (CESC), the rate is Rs.2.7/unit for the first 25 units consumed, then at the rate of Rs.3.3/unit for the next 35 units.

Therefore, Total cost $=25 \times 2.7+20 \times 3.3=$ Rs. 133.5

So, the total input cost for the production of CNT is Rs.133.5 (neglecting the cost of coal as too small as compared to the power consumption cost)

Now, the cost of the Carbon Nanotubes as per standards are stated in Table 2.

The amount of CNT produced in experiment is about $20 \mathrm{mg}$ [9]. The cost above is given in $\$$, so we consider $1 \$=$ Rs 50 and the package unit is in grams.
Thus, the total cost comes to be $\frac{20}{1000} \times 83 \times 50=$ Rs 83.

Therefore, it can be understood that as the input cost is greater than the output cost, optimisation is essential in this case.

\section{Optimising the Power}

$$
\begin{aligned}
& \text { Power }=P=V \times I \\
& \log P=\log V+\log I
\end{aligned}
$$

Taking, $\log P=x_{1} ; \log V=x_{2} ; \log I=x_{3}$

In all the experiments minimum voltage and current are taken as $30 \mathrm{~V}$ and $50 \mathrm{~A}$ respectively.

$$
\begin{aligned}
V & \geq 30, I \geq 50 \\
\log V & \geq 1.47, \log I \geq 1.69 \\
x_{2} & \geq 1.47, x_{3} \geq 1.69
\end{aligned}
$$

Therefore, $x_{1}=x_{2}+x_{3}, x_{2} \geq 1.47, x_{3} \geq 1.69$

Considering the power consumption rate as $2.7 /$ unit,

The total power can be calculated as $15 \times 2.7 \times P=$ $40.5 P$

For optimum result, $40.5 P \leq 83$

$$
\begin{gathered}
P \leq \frac{83}{40.5}=2.05 \mathrm{KW}=2050 \mathrm{~W} \\
\log P \leq 3.31 \\
x_{1} \leq 3.31
\end{gathered}
$$

Applying Simplex Algorithm,

$$
\operatorname{Min} x_{1}=x_{2}+x_{3}
$$

Subjected to the constraints,

$$
\begin{gathered}
x_{2}+x_{3} \leq 3.31 \\
x_{2} \geq 1.47 \\
x_{3} \geq 1.69
\end{gathered}
$$

Solving by graphical method, we get the following plotted and shown in Figure 1.

We plot the graph by taking equalities for the above constraints,

$$
\begin{gathered}
x_{2}+x_{3}=3.31 \\
x_{2}=1.47 \\
x_{3}=1.69
\end{gathered}
$$

The arrows shown on the particular line denoted the lesser-than-equal-to and greater-than-equal-to zone for the particular constraint line. The area enclosed by the three constraint lines gives the range of feasibility of the variables.

Therefore, we can conclude that, the enclosed region 


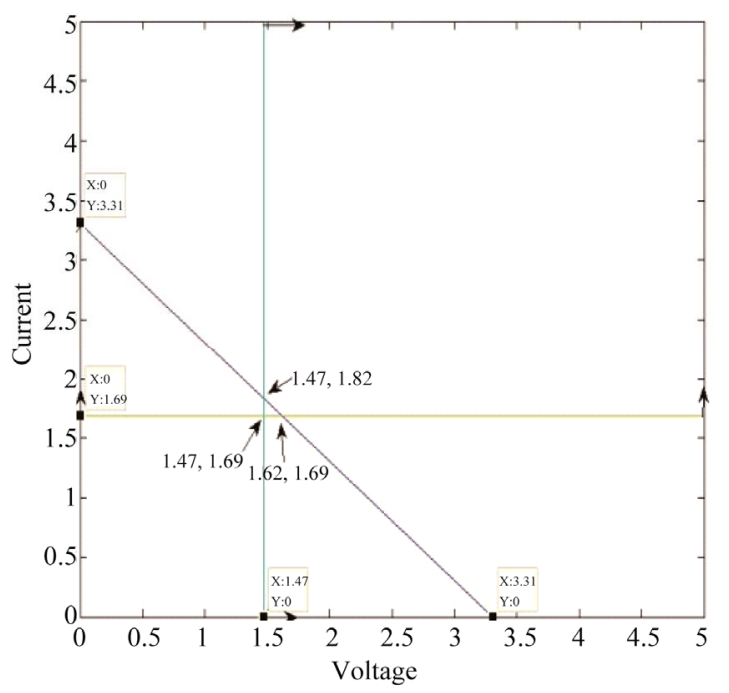

Figure 1. Solution graph of simplex optimisation process.

with the three lines, fit the feasible solution range.

$$
\begin{aligned}
& \operatorname{Max} x_{2}=1.62 \\
& \operatorname{Max} x_{3}=1.82
\end{aligned}
$$

The optimal range of the voltage and current can be defined as (by antilog of the results obtained):

$$
\begin{aligned}
& V=29.5 \sim 41.68 \mathrm{~V} \\
& I=48.97 \sim 66.07 \mathrm{~A}
\end{aligned}
$$

\section{Summary and Future Trends}

An optimisation of the main process parameters i.e. voltage and current, pertaining to the arc discharge process discussed in the paper. The result focuses on the feasible and optimum range of the parameters, based on the cost of the SWNT obtained as the product. It can be certainly perceived through calculation that if the voltage or the current cross the optimal range, the power consumption is increased and thus, the input cost is aggravated resulting in infeasibility of the production line.

However, still more scopes remain, as the major assumptions viz. the cost of power consumption is only confined to the unit power consumption cost fixed by CESC, can be made universal by programming the algorithm mentioned above, and a detailed analysis of the optimization by various other processes may lead to many valuable information in this virgin field.

\section{REFERENCES}

[1] Y. Y. Tsai, J. S. Su, C. Y. Su, "A Novel Method to Produce Carbon Nanotubes Using EDM Process," International Journal of Machine Tools \& Manufacture, Vol. 48, No. 15,2008 , pp. 1653-1657.

doi:10.1016/j.ijmachtools.2008.07.005

[2] J. S. Qiu, Y. F. Li, Y. P. Wang, T. H. Wang, Z. B. Zhao, Y. Zhou, F. Li and H. M. Cheng, "High-Purity Single Wall Carbon Nanotubes Synthesized from Coal," Carbon, Vol. 41, No. 11, 2003, pp. 2159-2179. doi:10.1016/S0008-6223(03)00242-2

[3] J. S. Qiu, F. Zhang, Y. Zhou, H. M. Han, D. S. Hu, S. C. Tsang and P. J. F. Harris, "Carbon Nano-Materials from Eleven Caking Coals," Fuel, Vol. 81, No. 11-12, 2002, pp. 1509-1514. doi:10.1016/S0016-2361(02)00069-8

[4] J. S. Qiu, Y. F. Li, Y. P. Wang and W. Li, "Production of Carbon Nanotubes from Coal," Fuel Processing Technology, Vol. 85, No. 15, 2004, pp. 1663-1670. doi:10.1016/j.fuproc.2003.12.010

[5] J. S. Qiu, Z. Y. Wang, Z. B. Zhao and T. H. Wang, "Synthesis of Double-Walled Carbon Nanotubes from Coal in Hydrogen-Free Atmosphere," Fuel, Vol. 86, No. 1-2, 2007, pp. 282-286. doi:10.1016/j.fuel.2006.05.024

[6] K. Kidena, Y. Kamiyama and M. Nomura, "A Possibility of the Production of Carbon Nanotubes from Heavy Hydrocarbons," Fuel Processing Technology, Vol. 89, No. 4, 2008, pp. 449-454. doi:10.1016/j.fuproc.2007.11.021

[7] J. L. Yu, J. Lucas, V. Strezov and T. Wall, "Coal and Carbon Nanotube Production," Fuel, Vol. 82, No. 15-17, 2003, pp. 2025-2032. doi:10.1016/S0016-2361(03)00189-3

[8] M. A. Wilson, H. K. Patney and J. Kalman, "New Developments in Formation of Nanotubes from Coal," Fuel, Vol. 81, No. 1, 2002, pp. 5-14. doi:10.1016/S0016-2361(00)00192-7

[9] K. A. Williams, M. Tachibana, J. L. Allen, L. Grigorian, S. C. Cheng, S. L. Fang, G. U. Sumanasekera, A. L. Loper, J. H. Williams and P. C. Eklund, "Single-wall Carbon Nanotubes from Coal," Chemical Physics Letters, Vol. 310, No. 1-2, 1999, pp. 31-37. doi:10.1016/S0009-2614(99)00725-3

[10] M. S. Krishnan "Classification of Coal," Geological Survey of India, Vol. 4, No.3, 1940, p. 552.

[11] "Domestic Coal Price Fixation," Coal India Ltd., 2011.

[12] http://www.helixmaterial.com/Ordering.html 